\title{
Basics of vitrectomy. Editors Rajvardhan Azad et al. (2019) 216 pp, 119 illustrations, Hardback ISBN: 9789385062339 Thieme Publishers New York/Stuttgart
}

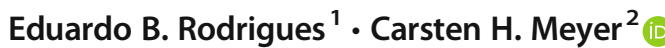 \\ Received: 27 June 2020 / Revised: 27 June 2020 / Accepted: 6 July 2020 / Published online: 15 July 2020 \\ (C) Springer-Verlag GmbH Germany, part of Springer Nature 2020
}

The authors present a comprehensive handbook for both fellows and young practicing vitreo-retinal consultants. Basics of vitrectomy is a well-structured hardcover booklet explaining all essential surgical steps in a well-written text with sequential intraoperative images. The authors are clearly thoughtful surgeons with a wide range of experience in the vitreo-retinal surgery.

This hardback cover book contains 14 chapters at first discussing the history, basic principles of vitreo-retinal surgery, and various surgical techniques or straightforward to interventions to manage the most frequent eye diseases like retinal detachment, macular surgery, diabetic retinopathy, as well as challenging complex procedures in ocular foreign body removal and retinopathy of prematurity. Each chapter includes practical surgical tips as well as detailed aspects for each specific situation. The handbook Basics of vitrectomy contains a number of useful tips, avoiding frequent errors, which is important to our everyday practice. We enjoyed reading this book, although the small handbook appears slightly overpriced. This book will serve as a useful practical guide for both fellows and practicing vitreo-retinal surgeons.

Publisher's note Springer Nature remains neutral with regard to jurisdictional claims in published maps and institutional affiliations.
Carsten H. Meyer

meyer_eye@yahoo.com

1 Saint Louis University Hospital - South Campus, 1755 S. Grand Blvd., St. Louis, MO 63104-1540, USA

2 Augenärzte Davos, Bahnnofstrasse 3, 7270 Davos Platz, Switzerland 